\section{La certeza simple de ser y su relevancia hoy según Edith Stein*}

\author{
Anneliese Meis**
}

RECIBIDO: 18-07-16. APROBADO: 31-08-16

RESUMEN: El estudio pretende dilucidar el significado de la "certeza de ser" en Edith Stein, fenómeno originario al cual el pensar filosófico-teológico se acerca con actitud crítica desde siempre, pero cuya intelección Stein despliega con rigor filosófico, al abrirla al misterio del espíritu finito, anticipado por el Espíritu infinito, expuesto al no-ser por falta de cobijo. En efecto, la certeza de ser trasciende la razón humana en su índole clara y distinta, aunque se gesta al interior de ella, a la vez que supera al sentimiento, sin tener su anclaje definitivo en él, por ser una novedad que emerge entre ambos.

Palabras clave: Edith Stein, certeza de ser, razón y fe, espíritu finito, Espíritu infinito.
The Simple Certainty of Being and its Importance Nowdays According to Edith Stein

AвSTRACT: This study aims at elucidating the meaning of Edith Stein's notion of "certainty of being". As an original phenomenon, the latter has always been critically approached by both Philosophy and Theology. Nonetheless, Stein provides a philosophically rigorous understanding of what "certainty of being" means, in which the mystery of the finite spirit -always exposed to not-being for its lack of shelteris seized by the infinite Spirit. Although related to both human reason and feelings, the "certainty of being" transcends them, for it implies something new beyond clear and distinct ideas, and mere emotions.

Key Words: Edith Stein, Certainty of being, reason, faith, Finite Sprit, Infinite Spririt.

\section{PARA CITAR ESTE ARTÍCULO:}

Meis, Anneliese. "La certeza simple de ser y su relevancia hoy según Edith Stein”. Theologica Xaveriana 183 (2017): 113139. https://doi.org/10.11144/javeriana. tx67-183.csrhes

* El artículo es producto de la investigación Fondecyt 2015-2016/1150136, "La certeza de ser: acercamiento histórico-sistemático a la encrucijada entre Tomás y Agustín en Edith Stein, 'Potenz und akt'. Anneliese Meis, investigadora responsable; Pamela Chávez y Mariano Crespo, coinvestigadores.

** Doctora en Teología, Pontificia Universidad Católica de Chile, Santiago de Chile. Profesora titular adjunta; directora del Centro Pontificia Universidad Católica, Estudios Interdisciplinarios en Edith Stein. OrCID: 0000-0002-9930-3751. Correo electrónico: ameis@uc.cl 


\section{Introducción}

Si bien la certeza se define como "conocimiento seguro" por medio de sus articulaciones experienciales, conceptuales, filosóficas y teológicas, resalta su ambigüedad terminológica en cuanto "saber cierto" -Gewissheit- y "saber asegurado" Sicherheit ${ }^{1}$, que atraviesa los estudios recientes de índole existencial ${ }^{2}$, religiosa ${ }^{3}$, filosófica ${ }^{4}$ y teológica pero que Edith Stein, pensadora potente, que de agnóstica pasó a ser católica, desentraña para ofrecer una novedad de sorprendente actualidad ${ }^{6}$.

En efecto, Stein, discípula de Husserl, no solo encara críticamente la relevancia de la certeza en la investigación, sino ofrece una comprensión de ella elaborada con nitidez y finura metódica ${ }^{7}$. De hecho, la certeza de ser trasciende la razón humana en su índole clara y distinta. Sin embargo, es preciso reconocer que dicha certeza se gesta al interior de la razón y, al mismo tiempo, supera al sentimiento, sin tener su anclaje definitivo en él, dado que representa una novedad que emerge entre ambos, cuando

\footnotetext{
${ }^{1}$ Halbfass, Historisches Wörterbuch der Philosophie, 3 592-594.

${ }^{2}$ Habermas, El discurso filosófico de la Modernidad, 150. El autor se refiere a filósofos de la Modernidad que contribuyen de diversas maneras a la comprensión de la certeza, como afirma respecto de Heidegger: "La originalidad de Heidegger radica en cómo interpreta en términos de historia de la metafísica la dominación que el sujeto moderno ejerce. Descartes ocupa, por así decirlo, el centro entre Protágoras y Nietzsche. Entiende la subjetividad de la autoconciencia como el fundamento absolutamente seguro de la representación, con ello el ente en su totalidad se trueca en mundo subjetivo de objetos representados, y la verdad en certeza subjetiva" (ibíd., 150).
}

${ }^{3}$ Berger y Zijderveld, In Praise of Doubt. How to Have Convictions Without Becaming a Fanatic, 89-119, "Certainty and doubt". El autor observa, al referirse a Robert Musil: "The voice of truth has a suspicious undertone" (ibid., 89). "Yet there is in fact a very fundamental non-religious and non-philosophical certainty in our lives, one that offers what Arnold Gehlen aptly called "a being certainty" (ibid., 92). His "being certainty is a largely taken, forgranted certainty of institutions, which are transmitted from generation to generation, establishing what's called tradition, Mariage, family, church-indubitable" (ibid., 92).

${ }^{4}$ Fermandois, "Ni fundacionismo ni coherentismo, 99-117. Según Wittgenstein: “El mismo concepto de certeza, tal como se explicita en el texto que lo tiene por título, conlleva una inconfudible marca antiintelectualista. Se trata de la seguridad con que los seres humanos desplegamos determinadas técnicas en práctica normativas en las cuales participamos" (Wittgenstein, Sobre la certeza, 114ss.)

${ }^{5}$ Naaykens, "El fundamento de nuestra certeza", 171-194. Mientras Marion, en Certitudes négatives, ofrece un fascinante análisis de las "certezas negativas", abriendo el trasfondo filosófico de la teología negativa, el papa Francisco, en "La certeza de la resurrección”, 626, afirma categóricamente: “...la certeza de la resurrección”.

${ }^{6}$ Stein, Gesamtausgabe, hrsg Internationales Edith Stein; ídem, Potenz und Akt. Studien zu einer Philosophie des Seins; ídem, Endliches und ewiges Sein. Versuch eines Aufstiegs zum Sinn des Seins; ídem, Anhang: Martin Heideggers Existenzphilosophie. Die Seelenburg.

${ }^{7}$ Stein, "Psychische Kausalität", 5-11. 
el espíritu finito es anticipado por su fundamento último, el Espíritu infinito, y se entrega a él, al modo del Espíritu Santo ${ }^{8}$.

Tal comprensión de la certeza se pretende dilucidar a lo largo de la obra steineana por medio de análisis textuales, en interrelación y contraste con estudios actuales, relevantes hoy sin poder ofrecer cierta articulación personal de tipo crítico?.

\section{La certeza simple de ser en cuanto punto de partida en acto y potencia y ser finito y ser eterno}

Stein explica la certeza de ser como punto de partida de todo quehacer científico, afirmando: “...una certeza simple: cogito, sum pensando, sintiendo, queriendo o como siempre moviéndome espiritualmente, soy yo y soy consciente de este ser" ${ }^{\prime \prime}$. Esta afirmación del Capítulo I de Acto y potencia es precisada en el Capítulo II de Ser finito y ser eterno, cuando la autora señala: "Cada vez que el espíritu humano, en su búsqueda de la verdad, ha partido de un punto indudable, se ha encontrado con este hecho inevitablemente cercano: el hecho del propio ser..."

En este sentido, Stein pregunta: "De todo lo que sabemos, ¿qué conocemos de la misma manera que sabemos que vivimos?” Y contesta: “En este saber no tememos ser engańados por ninguna apariencia de la verdad, puesto que es seguro que incluso aquel que se engaña, vive", verdad no del todo evidente hoy ${ }^{12 .}$

\section{Hacia la pregunta por el ser}

La comprensión steineana de la certeza simple de ser a partir del yo vivo precede a todo conocimiento:

...no como si de allí -como de un principio- derivara todo lo demás en una secuencia lógica o como si fuera la medida en que todo lo demás deba ser

\footnotetext{
${ }^{8}$ Ver a Meis, "El espíritu finito, anticipado por el Espíritu infinito en la obra Potenz und Akt de Edith Stein". ${ }^{9}$ Ídem, notas 2, 3, 4, 5: pese a las entradas metodológicas diferentes, hay coincidencias y oposiciones.

${ }^{10}$ Stein, Potenz und Akt, 9ss. [En español: Acto y potencia, 247].

${ }^{11}$ Ídem, Endliches und ewiges Sein, 40. [Ser finito y ser eterno, 645].

${ }^{12}$ Esto puede apreciarse en Jürgen Habermas cuando se refiere a Searle: "Searle ha reaccionado a esta dificultad con la restricción de que el significado literal de una oración no fija por entero las condiciones de validez del acto de habla en que esa oración se emplea, sino que ese significado tiene que ser completado tácitamente mediante un sistema de suposiciones de fondo acerca de la normalidad de estados generales del mundo. Estas certezas de fondo prerreflexivas, son de naturaleza holística; no pueden agotarse mediante un conjunto finito numerable de especificaciones (227). Mantiene una relación igualmente estrecha con la totalidad del mundo de la vida y con el sano sentido común, aunque, eso sí, socava subversivamente y sin miramiento alguno las certezas de la práctica cotidiana” (Habermas, El discurso filosófico de la Modernidad, 216).
} 
medido, sino en el sentido del punto de partida, detrás del cual no se puede retroceder. La certeza de ser es una certeza irreflexa, que precede a todo conocimiento racional. ${ }^{13}$

Sin embargo, en cuanto tal es "el conocimiento más originario", "en el sentido de lo que me está más cerca, es inseparable de mí y constituye un punto de partida detrás del cual es imposible ir más atrás" ${ }^{14}$, ya que "el espíritu sale de la actitud originaria de su vida orientada hacia los objetos a fin de considerarse a sí mismo"; pero "cuando en el curso de tal retorno el espíritu se sumerge en el simple hecho de su ser, este le sugiere una triple pregunta: ¿Qué es el ser del cual estoy consciente?”. Esta pregunta es, por cierto, actual ${ }^{15}$.

\section{El "simple hecho de ser" y el yo}

La autora advierte:

Si el intelecto se adentra en esta certeza, ella se divide en una triple problemática: (1) ¿Qué es el ser del cual está consciente: innesein? (2) ¿Qué es el yo que está consciente de su ser? (3) ¿Qué es el acto o el movimiento espiritual -Regung-en el cual soy consciente de mí y de él: bewusst? ${ }^{16}$

Estas preguntas involucran tanto el ser como el no-ser, pues, el "yo soy" no aguanta la mirada. El "en el cual soy", el acto, es cada vez otro y como el ser y el acto no son separables, porque estoy "dentro de él”, el ser también es otro cada vez; el ser de "antes" es pasado y ha concedido su lugar al ser "de ahora". El ser del que soy consciente como mi ser no es separable de la temporalidad. Es como ser actual, puntiforme - puntuell-, un "ahora" entre un "ya no" y un "todavía no" ${ }^{17}$; pero al dividirse en su carácter fluido en ser y no-ser, se nos revela la idea del ser puro, que no tiene nada en sí del no ser, en el cual no hay "ya no" y "todavía no", que no es temporal, sino eterno. De este modo, el ser eterno y el ser temporal, incambiable y cambiable, y también el no ser son "ideas con que el intelecto se topa por sí mismo y no son prestadas de otra parte" 18 .

\footnotetext{
${ }^{13}$ Stein, Potenz und Akt, 10 [Acto y potencia, 247].

${ }^{14}$ Ídem, Endliches und Ewiges Sein, 41 [Ser finito y ser eterno, 646].

${ }^{15}$ Ibíd., 41ss. [646]. Ver a Fermandois, "Ni fundacionismo ni coherentismo"; Wittgenstein también formula: “...podemos ahora preguntarnos: ¿De dónde provienen las certezas básicas? ¿Cuál es su origen? O quizás menos metafóricamente: ¿Cómo las aprendemos?” (Wittgenstein, Sobre la certeza, 112). La respuesta de este filósofo permite comprender por contraste la profundidad de la pregunta de Stein.

${ }^{16}$ Stein, Endliches und Ewiges Sein, 42 [Ser finito y ser eterno, 646ss.].

${ }^{17}$ Ibíd., 43 [646ss.].

${ }^{18}$ Ídem, Potenz und Akt, 10 [Acto y potencia, 248 ].
} 
Esta verdad la hace suya una filosofía que toma en serio la analogia entis ${ }^{19}$ en cuanto "relación de origen" -Ursprungsbeziehung ${ }^{20}$ - el "hecho de partida": Ausgangstatsache:

El ser presente-real del momento mismo no es pensable como subsistente solo para sí mismo, del mismo modo, que no se puede imaginar el punto fuera de la línea y el momento mismo sin una duración temporal, y si consideramos en el modo de la conciencia, se da como una cosa que, saliendo de la oscuridad, pasa un rayo de luz, para después hundirse en la oscuridad; o como la cresta de una ola que pertenece a una corriente; todas estas imágenes describen un ser que es permanente pero que no es actual a lo largo de toda su duración. ${ }^{21}$

Esto significa lo siguiente: "La actualidad y la potencialidad están contenidas como modos de ser en el simple hecho de ser y deben ser deducidas de él. La potencialidad $[\ldots]$ no es no-ser. Es algo entre ser y no ser simultáneamente”. El ser, entonces, revela una ligazón profunda con el yo en cuanto

...yo "todavía" soy lo que era antes, y [...] soy "ya" lo que seré en el porvenir, ambos pertenecen a mi ser presente; mi ser pasado y futuro, como tal, es completamente nulo; yo soy ahora, no antes ni más tarde, solo por el hecho de que en el recuerdo y en la expectativa conservo espiritualmente mi pasado y mi futuro dentro de un cierto ámbito, no rígidamente "delimitado", pues de hecho mi ser se encuentra como sobre el filo de una navaja. ${ }^{22}$

Sin embargo: "Lo que aquí se nos muestra separadamente es uno en Dios". "Dios es 'el que es'; este es el nombre con el cual se designó él mismo (Ex 3,14), y este nombre, según Agustín, expresa de la mejor forma lo que es: De Trinitate I 1"23.

Ahora bien, si Tomás dice que el que recibe el ser está "en potencia" en relación con el ser que recibe, considera al ser mismo como acto. Por el contrario, "potencia" en sentido estricto, no es "ser posible", sino "posibilidad de ser" u orientación hacia el ser real. Lo que es realmente o lo que puede llegar a ser está in actu o in potentia, actual o potencial. Ser actual y ser potencial, ser real y ser posible expresan, pues, los modos de ser de algo que se asume en ellos.

${ }^{19}$ Ídem, Endliches und Ewiges Sein, 42 [Ser finito y ser eterno, 647].

${ }^{20}$ Ibíd., 43 [648].

${ }^{21}$ Ibíd., 43 [648].

${ }^{22}$ Ibíd., 44 [649]. Constatación steineana profundísima que contrasta Habermas, cuando afirma: "El concepto de autorreflexión cobra la primacía, y la relación del sujeto representador consigo mismo se convierte en único fundamento de cualquier certeza última. El fin de la metafísica es el final de una coordinación entre cosas y representaciones, objetiva, efectuada, por así decirlo, mudamente por el lenguaje y que por ello permaneció aproblemática" (Habermas, El discurso filosófico de la Modernidad, 284).

${ }^{23}$ Stein, Endliches und Ewiges Sein, 46 [Ser finito y ser eterno, 651ss.]. 
Acto y potencia son nombres para modos de ser en sí e independientemente de lo que ellos implican, pero se encuentran ligados al "movimiento espiritual" de la "unidad de vivencia”, decisiva para comprender la certeza simple de ser: “...mi ser presente es actual y potencial a la vez. Actualidad y potencialidad están contenidas como modos de ser en el simple hecho de ser-Seinstatsache" 24. Sin embargo, ¿qué significa el yo-me-encontrarse? Estoy dentro conscientemente. Yo no dividido... el yo pensante es el mismo yo; pero ¿qué me es consciente?25

Las preguntas dilucidadas por Stein por medio del ejemplo de la alegría clarifican su relación con el yo:

La vivencia del contenido "alegría" está condicionada por dos factores: por el "objeto" y por el "yo". El objeto -en este caso el contenido de la noticia- no pertenece como "parte de la alegría en cuanto al contenido de vivencia, pero sí pertenece la dirección hacia el objeto, forma parte de ella en cuanto "intención" [...] yo no puedo experimentar nada sin que el "yo" esté presente en cuanto participante de la experiencia. Pero, ¿qué clase de "yo" es este? Existe entonces "en mí" cierta cosa -y hasta varias- que no me es desconocida. En ese sentido, el yo no pertenece al contenido de la vivencia; está más allá de la vivencia, en modo similar, aunque no del todo idéntico como el objeto, al que se orienta la vivencia ${ }^{26}$

Sin embargo, si yo soy en el mismo momento el mismo y otro, esto permite preguntar:

¿No hallo aquí una profundidad que se abre a la vida actual? ¿No es esto una manifestación de algo que está detrás, que no es comprensible él mismo, ni lo es directamente? ¿No se da aquí una primera dirección en la que la inmanencia señala algo más allá de sí misma, y nos fuerza a salir de ella?27

Hay entonces algo para el flujo de vida que está en la base, " $z u$ Grunde liegt", lo que le sostiene. Con esto, la búsqueda por entender la certeza del ser, se encuentra con lo que permanece, lo seguro, la substanz.

\section{El sostén: el yo y la sustancia}

Lo que sostiene al yo es "algo", no directamente manifiesto, pero seguro. No obstante:

Yo no puedo directamente tener en cuenta este algo: que lo es, como y lo que es, se me manifiesta en lo que para mí inmediatamente es seguro y lo que

\footnotetext{
${ }^{24}$ Ídem, Potenz und Akt, 10 [Acto y potencia, 249].

${ }^{25}$ Ibíd., 10 [251ss.]

${ }^{26}$ Ídem, Endliches und Ewiges Sein, 46 [Ser finito y ser eterno, 656ss.].

${ }^{27}$ Ídem, Potenz und Akt, 14 [Acto y potencia, 252].
} 
ahora, tan pronto este algo aparece por detrás, emerge como manifestación, repercusión, actividad de este algo. ${ }^{28}$

Esto significa que tenemos acceso al acto como confirmación de una sustancia, pese a que las categorías algo, acto y sustancia no se encuentran todas en el mismo nivel. De hecho, "algo" en la esfera inmanente es la suprema y más general categoría lógica: no está delimitado a alguna esfera, sino tanto lo inmanente como lo trascendente entran en ella. Mientras yo y sustancia son delimitaciones; es decir, el yo se encuentra en la inmanencia, aunque aplicado a la trascendencia, ya que está detrás el yo puro, consciente de sí mismo. Por su parte, la sustancia apunta a la esfera trascendente, que no tiene lugar en la inmanente.

Entonces, "el ser del yo en relación con algo que todavía no es, pero para lo que está equipado, nos abrió la duración del yo, y su cualificación cambiante el acceso a algo que está detrás" ${ }^{29}$, que no solo posibilita que la sustancia, acto y potencia se complementen, sino que verifica la certeza de ser a partir de su nivel más profundo, ya no designado sustancia, sino yo: este yo atestigua la certeza en las esferas del ser inmanente, trascendente y absoluto.

\section{Las tres esferas del "hecho simple de ser"}

\section{Cuando Stein constata:}

Partiendo de un hecho simple, inmediatamente cierto - gewiss- del ser hemos llegando a una división de tres esferas del ser: la esfera inmanente como la que nos es inmediata e inseparablemente cercana y consciente; la trascendente, que se anuncia en la inmanencia; $y$ una tercera que según su ser es radicalmente diferente de la inmanente como de aquella primera trascendente. ${ }^{30}$

Entonces pasa ella a preguntar:

¿Qué me sostiene en mi existencia puntual entre ser y no ser? Si penetré en la esfera trascendente, puedo comprender la sustancia como soporte de este ser, pero no plenamente, ya que la potencialidad apunta a actualidad, que se cumple: ¿puede algo dar contención a mi ser frágil, sino el ser verdadero? ${ }^{31}$

Stein insiste en esta pregunta por lo siguiente:

¿Puede otra cosa dar un apoyo a mi ser caduco que descansa punto por punto en una auténtica existencia, sino el verdadero ser en el que no hay nada de no-

\footnotetext{
${ }^{28}$ Ibíd., 14 [252]. Como aparece transcrito es cita textual de la traducción oficial.

${ }^{29}$ Ibíd., 15 [253].

${ }^{30}$ Ibíd., 16 [254].

${ }^{31}$ Ibíd., 17 [254-255].
} 
ser, que de sí solo es inmutable y no necesita de ningún apoyo? ¿Y la caducidad de mi propio ser acaso no da seguridad no solo de la idea, sino de la realidad de este ser puro, verdadero "absoluto"?32

Emerge aquí la cercanía del yo al ser absoluto, que hace del yo "un ente en sentido eminente" en cuanto despierta la pregunta por la "relación del que sostiene y del que es sostenido". Sin embargo:

¿El yo ha tenido igualmente un comienzo de su ser? Su experiencia inmediata no le da ninguna respuesta sobre este punto, así como tampoco sobre su posible fin. En diferentes puntos de su ser se abre un vacío: ¿Viene de la nada? ¿Va hacia la nada? ¿El abismo de la nada puede abrirse bajo sus pies en cualquier momento? Qué débil nos parece de repente el ser del yo, del cual hemos dicho hace un momento que era el ente por excelencia e, incluso, doblemente excelente: en cuanto siempre vivo frente a lo que ya no es vivo o a lo que no lo es todavía, y en cuanto que soporta frente a lo que es soportado, que le debe la cima de la vida. ${ }^{33}$

Si bien "el yo da vida a los contenidos y como tal no puede ser nada", la autora no admite una "esfera de dominio ilimitado", ya que pregunta:

¿El yo es una fuente de vida? Puesto que la vida es el ser del yo, esto significaría al mismo tiempo que tendría su ser por si mismo. Pero obviamente esto no va de acuerdo con los rasgos particulares que hemos constatado en este ser, a saber: el misterio de su origen y su fin, las lagunas no colmadas de su propio pasado, la imposibilidad de llamar aquello que pertenece a este ser (contenidos) a la existencia por propio poder, $y$ mantenerlo allí, y ante todo cómo es el yo mismo y cómo vivencia su propio ser. ${ }^{34}$

Se abre aquí una interrelación del yo con el misterio del origen y fin que se evidencia para la autora al remontar, efectivamente, a que el yo no puede autoproducirse sino que "se encuentra como una cosa viva, como ser presente, y al mismo tiempo como proveniente de un pasado y prolongándose hacia un futuro: el yo mismo y su ser están inevitablemente alli"3s.

Este "estar inevitablemente alli" de un ser que es desde sí mismo evoca una vez más la relación entre ser y tiempo:

El ser del yo es algo que vive de momento en momento. Y no puede "parar", puesto que huye "imparable". Así no llega jamás verdaderamente a poseerse a sí mismo. Por eso estamos obligados a designar al ser del yo, este presente con-

\footnotetext{
${ }^{32}$ Ibíd., 17 [255].

${ }^{33}$ Ídem, Endliches und Ewiges Sein, 55ss. [Ser finito y ser eterno, 662].

${ }^{34}$ Ibíd., 56 [663].

${ }^{35}$ Ibíd., 56ss. [663].
} 
tinuamente cambiante, como una cosa recibida. Está puesto en la existencia y allí está conservado de un instante al otro. De esta manera se da la posibilidad de un comienzo y un fin y también de la interrupción de su ser. ${ }^{36}$

La autora llega aquí a un dato decisivo, el carácter recibido del ser, que implica la relación del yo con el otro, pues ¿de dónde viene este "carácter recibido del ser"? Efectivamente:

...el hecho de recibir el ser independientemente del ser eterno es impensable, puesto que no hay nada fuera de este que pueda estar realmente en posesión del ser. Todo lo finito es una cosa puesta-en-el-ser y conservada en el ser; por esta razón incapaz de dar y de conservar el ser por sí mismo. [...]. Mi ser, tal como yo lo encuentro y tal como yo me encuentro en él, es un ser nulo [...]. Las unidades vivenciales cuyo ser es un devenir y un pasar tienen necesidad del yo para llegar a ser, pero el ser que reciben por medio del yo no es eterno e inmutable; es más bien solo este devenir y este pasar con cierto nivel de ser en el momento del pasado del devenir al desaparecer. El yo parece estar más cerca del ser puro, puesto que no llega solamente por un solo momento a la cima del ser, sino que es conservado en el ser en cada instante: ciertamente no en cuanto al ser sin cambio, sino en cuanto que posee un contenido de vida continuamente cambiante. ${ }^{37}$

La transposición de la oposición de ser y cambio en "un contenido de vida continuamente cambiante" abre la índole recibida del ser hacia su verdad eterna:

El yo puede llegar a la idea del ser eterno no solamente partiendo del devenir y del cesar de sus contenidos de vivencias, sino también partiendo de la particularidad de su ser que se prolonga de un instante a otro: retrocede con horror ante la nada y exige no solamente una continuación sin fin de su ser, sino también una posesión plena del ser: de un ser que podría abrazar todo su contenido en un presente sin cambio en lugar de ver constantemente desaparecer lo que acaba de llegar a la vida. Así se llega a la idea de la plenitud, borrando de su propio ser aquello de lo cual él tiene conciencia como de una insuficiencia, pero admitiendo en sí mismo grados de acercamiento a la plenitud del ser. ${ }^{38}$

En este argumento Stein llega a un "nexo entre actualidad y potencialidad", que no es el mismo que existe en las unidades de vivencias:

Si designamos el ser real como acto, entonces se oponen al acto puro en cuanto ser perfecto, inmutable y eterno, al ser que abraza toda plenitud con la mayor vitalidad imaginable, los actos finitos en cuanto imágenes infinitamente débiles y que traen consigo grados diversos; a ellos, a su vez, les corresponden como grados preliminares las diferentes potencias: el acto finito; sin embargo,

\footnotetext{
${ }^{36}$ Ibíd., 57 [664].

${ }^{37}$ Ibíd., 57 [665].

${ }^{38}$ Ibíd., 58 [665].
} 
en el campo que estamos considerando en este momento, en primer lugar y propiamente dicho, el ser del yo, y las unidades de vivencias participan solamente por el yo. ${ }^{39}$

Es entonces "el ser del yo" el que da consistencia a los diversos grados preliminares del acto finito en calidad de potencia en interrelación con el ser eterno.

Pese a que Stein no pretende saltar a la trascendencia, avanza en esta dirección, abriendo las diversas esferas hacia su interconexión:

Quisiera afirmar que pensando se haya de llegar a esta conclusión de que en el simple hecho de ser está dado el fundamento para una demostración de Dios. Pero con esto no se ha dicho que la seguridad de la existencia del ser absoluto esté dada inmediatamente en el simple hecho de ser. Yo tengo esta certeza en el momento en que creo: entonces me agarro al apoyo absoluto y me siento sostenido por él. ${ }^{40}$

En efecto, se trata aquí de una afirmación relevante para la certeza simple de ser, que se da, pero no se impone, sino que se abre en la fe, pensando; pero en definitiva hace falta el "asir" libremente el apoyo absoluto por el cual me siento sostenido para acoger la certeza del ser absoluto.

\section{La certeza del ser absoluto}

Stein explica la certeza del ser simple a partir de la semejanza con mayor desemejanza en cuanto certeza de la fe, "que es una seguridad ciega, creer es no ver. Y es sin duda posible que sea consciente de su ser actual sin que en ello se tenga que realizar un acto de fe o también tener solo una fe inactual" ${ }^{41}$. De hecho, esta certeza involucra la índole actual e inactual de la fe, pero no como un simple belief, sino como acogida de la presencia de Dios.

Hay entonces una certeza del total ser sostenido, una seguridad de la presencia de Dios que va más allá de la certeza de la fe y que ya no es ciega: todo místico sabe testificar esto. Pero el místico ser consciente de Dios, no está unido inseparablemente del simple hecho de ser. Si así fuera, entonces no habría ya lugar para la fe. ${ }^{42}$

Vale decir que la certeza de la fe en la presencia de Dios "está unida inseparablemente al simple hecho de ser". De este modo, no se trata de dos esferas separables, definitivamente, sino interrelacionadas, aunque complejas:

\footnotetext{
${ }^{39}$ Ibíd., 59 [666].

${ }^{40}$ Ídem, Potenz und Akt, 17 [Acto y potencia, 255].

${ }^{41}$ Ibíd., 17 [255].

${ }^{42}$ Ídem, Potenz und Akt, 17 [Acto y potencia, 255].
} 
Entonces habrá que decir que la esfera del ser absoluto hay que ponerla como una segunda esfera trascendente; y lleva a ella desde lo inmanente un triple camino: el de la contemplación mística, el de la fe, el del método lógico. El primero es forzoso, pero no es un camino ordinario; el segundo está abierto a todos, pero la voluntad debe ayudar para llegar a la meta; el tercero es el camino del conocimiento natural, el que todo ser racional podría seguir; por qué esto no sucede, por qué no sólo el torpe y el indiferente, sino también el teóricamente interesado se detienen ante este camino, por qué se ha empleado ya tanta energía para demostrar su impracticabilidad, esto es tan insondable como el misterio mismo de un ser fuera de Dios o contra Dios. ${ }^{43}$

No cabe duda de que en el análisis reflexivo del propio ser y su futilidad emerge la vida en su certeza incuestionable a través de una mirada retrospectiva:

El análisis racional retrospectivo de nuestro ser muestra que existen pocas razones para que tal seguridad se encuentre en él mismo y cómo, de hecho, este está expuesto a la nada. ¿Esta seguridad del ser está probada como objetivamente sin fundamento y por tanto como "racional"? ¿Y como actitud razonable de vida, una libertad hacia la muerte, apasionada [...] segura de sí misma y angustiante? De ninguna manera. Porque, al hecho innegable de que mi ser es fugaz y se prolonga de un momento a otro y se encuentra expuesto a la posibilidad del no-ser, le corresponde otro hecho también innegable de que yo, a pesar de esta fugacidad, soy y soy conservado en el ser de una instante a otro; en fin, en mi ser fugaz, yo abrazo un ser duradero. ${ }^{44}$

El "otro hecho también innegable" que emerge del análisis pensante de la nulidad de mi ser me permite "abrazar un ser duradero", fundamento último de la certeza de ser simple. En efecto, la autora argumenta:

Yo me sé sostenido y este sostén me da tranquilidad y seguridad; ciertamente no es la confianza segura de sí misma del hombre que, con su propia fuerza, se mantiene de pie sobre el suelo firme, sino la seguridad dulce y feliz del niño que reposa sobre un brazo fuerte, es decir, una seguridad que, vista objetivamente, no es menos razonable. En efecto, el niño que viviera constantemente en la angustia de que su madre le podría dejar caer, ¿sería "razonable"?45

Esta certeza de ser simple la explicita Stein más detenidamente cuando afirma:

En mi ser yo me encuentro entonces con otro ser que no es el mío, sino que es el sostén y el fundamento de mi ser que no posee en mí mismo ni sostén ni fundamento. Puedo llegar por dos vías a ese fundamento que encuentro dentro de mí mismo a fin de conocer al ser eterno. La primera es la de la fe: si

\footnotetext{
${ }^{43}$ Ibíd., 17-18 [255]. El texto original indica zwingend, lo que significa que convence.

${ }^{44}$ Ídem, Endliches und Ewiges Sein, 59 [Ser finito y ser eterno, 667].

${ }^{45}$ Ibíd., 59ss. [667].
} 
Dios se revela como "el ente cocreador" y "conservador" y si el Salvador dice: "Aquel que cree en el hijo tiene la vida eterna", estas son respuestas claras a la cuestión enigmática que concierne a mi propio ser. Y si Dios me dice por la boca del profeta que me es más fiel que mi padre y mi madre y que él es el amor mismo, reconozco cuán "razonable" es mi confianza en el brazo que me sostiene y cómo toda angustia de caer en la nada es insensata, mientras yo no me desprenda por mí mismo del brazo protector. ${ }^{46}$

Stein explica esta certeza a través de referencias a Agustín, cuando afirma:

La seguridad de ser que yo siento en mi ser fugaz indica un anclaje inmediato en ese sostén y este fundamento último de mi ser (a pesar de sostenes indirectos posibles). Esto significa seguramente una percepción muy oscura que apenas es posible llamar "conocimiento". Según San Agustín: "Quizá alguien piense que, aun en esta existencia mortal, puede ocurrir a un hombre que [...] llegue a poseer la luz serenísima de la verdad inmutable y que, apartada completamente el alma de la costumbre de esta vida, se adhiera a ella en forma constante e indefectible. Ese tal no entiende "...qué es lo que busca en quien es el que lo busca $[. .$.$] . Cuando, siendo semejante, comiences a acercarte y a percibir$ perfectamente a Dios, tanto cuanto en ti crezca la caridad, puesto que Dios es caridad, percibirás algo de lo que decías y no decías. Pues antes de que percibieras, pensabas que dabas a conocer perfectamente a Dios; pero comienzas a percibirle, y adviertes que no puedes expresar lo que percibes. ${ }^{47}$

La certeza que emerge así de la argumentación agustiniana, hecha suya por Edith Stein, remonta a la presencia de Dios experimentable en la vida, pero no del todo clara y distinta, sino más bien mediante un descubrimiento permanente, pese a toda su certeza inacabada, pero propiamente teológico: "Este sentimiento oscuro nos hace asir lo inasible como inevitablemente cercano, aquel en el cual 'vivimos, nos movemos y somos', pero inasible".

El pensamiento argumentativo formula conceptos claros, pero estos no pueden asir al inasible: más todavía, lo sitúan en esa lejanía que es propia de todo lo que es conceptual. El camino de la fe nos da más que el del conocimiento filosófico; el camino de la fe nos conduce al Dios personal y cercano, al amante y al misericordioso y nos da una certeza que no se encuentra en ninguna parte en el conocimiento natural.

Sin embargo, también el camino de la fe es un camino oscuro. Dios mismo baja el tono de su lenguaje a la medida del hombre, a fin de volver asible al inasible.

Porque también en aquella misión que dio a su siervo Moisés cuando le dijo: Yo soy el que soy; y dirás a los hijos de Israel: "El que es me envió a vosotros", porque

\footnotetext{
${ }^{46}$ Ibíd., 60 [667].

${ }^{47}$ Ibíd., 61 [668ss.].
} 
era difícil comprender a la mente humana el mismo propio ser y era enviado un hombre a los hombres, bien que no por hombre [...]. Por eso dijo: Vete y di a los hijos de Israel: "El Dios de Abrahán, el Dios de Isaac, el Dios de Jacob, me envió a vosotros; este es mi nombre eternamente [...]". Lo que dije: Yo soy el que soy, es verdad, pero tú no lo comprendes; sin embargo, lo que dije: "Yo soy el Dios de Abrahán, el Dios de Isaac, el Dios de Jacob, también es verdadero y lo entiendes". Pues lo que dije: "Yo soy el que soy, se refiere a mí; y lo que dije (Yo soy) el Dios de Abrahán, el Dios de Isaac, el Dios de Jacob, te pertenece a ti". ${ }^{48}$

Para sintetizar: puede apreciarse que la "certeza de ser simple" es el punto de arranque originario que Stein ofrece para todo método científico, tanto filosófico como teológico. Esto hemos indagado en nuestro esfuerzo por verificar que dicha certeza emerge del sentir en cuanto nexo misterioso entre el espíritu y el cuerpo, abierto al Espíritu infinito. Tal verdad, articulada con maestría en Acto y potencia y en la obra maestra Ser finito y ser eterno surge ya a través de la investigación de otras obras steineanas, con diferentes énfasis y expresiones a partir de otros accesos que auscultamos a continuación.

\section{Accesos a la certeza simple de ser en Introducción a la filosofía, ¿Qué es filosofía? y La estructura de la persona humana, anteriores a Acto y potencia}

Entre las obras anteriores a Acto y potencia, en las cuales Stein se refiere a la comprensión de la "certeza simple de ser" -no como punto de partida-, destacan los aportes de Introducción a la filosofía, ¿Qué es filosofía? y La estructura de la persona humana, obras anteriores en las cuales la autora entreteje su preocupación por la certeza de una filosofía en cuanto "ciencia estricta" -Husserl-, con la dilucidación del método fenomenológico y la estructura del ser humano.

\section{La certeza absoluta y la duda en Introducción a la filosofía}

En la obra Introducción a la filosofía, de difícil reconstrucción, pero escrita antes de su conversión, Stein explica la certeza de ser, considerando lo absoluto (la "absolutez", en palabras de Stein) de la certeza en el campo propio de la filosofía. Esto, debido a que "la imposibilidad, por parte de la experiencia, de alcanzar conocimientos filosóficos" hace del "terreno de investigación de la filosofía" "un campo de absoluta certeza"49. Aquí emerge la absolutez de la certeza de Acto y potencia, pero ya no es la certeza de

${ }^{48}$ Ibíd., 61 [669].

${ }^{49}$ Ídem, Einführung in die Philosophie, 16 [Introducción a la filosofía, 681]. 
la filosofía, sino la del "ser absoluto" que interesa en Acto y potencia, de tal modo que Stein, efectivamente, "cambió esta idea en favor del conocimiento teológico" ${ }^{50}$. Stein sostiene, ya en Introducción a la filosofía, si "no se toma la posibilidad de la duda [...] como un punto de transición metodológica, entonces no es posible probar, mediante una demostración rigurosa, la certeza de lo que se pone en duda"s1.

Stein advierte: "Hay que añadir un criterio complementario [...] un factor inmanente, por el cual el conocimiento mismo se muestra como válido: este criterio es su comprensibilidad"s2. Tal "comprensibilidad" se explica en relación con la certeza:

$\mathrm{Si}$ nosotros, con nuestros propios ojos, podemos convencernos de que algo es o que es de tal o cual manera, entonces tenemos la certeza de que ese algo es "en verdad" como nosotros pensamos. Lo de "con nuestros propios ojos" hay que entenderlo cum grano salis. ${ }^{53}$

Puede apreciarse aquí la captación en cuanto fruto de lo visto "con nuestros propios ojos", actitud que en Acto y potencia marca la búsqueda de la certeza en cuanto percepción. La autora admite:

Si falta un motivo para decidirse a favor de una o de la otra posibilidad, entonces en vez de la creencia en la percepción o de la creencia en la empatía surge un estado de suspensión, de incertidumbre, una duda o también una sospecha, cuando hay algo que habla en favor de una de las dos posibilidades, pero que no lo hace de manera irrebatible. ${ }^{54}$

Esto significa que la certeza en cuanto proceder metódico no es absoluta, cuando se trata de "percepción” o "creencia en la empatía” en cuanto "estado de suspensión". Esta facilita las "intuiciones", "precisamente de este objeto -eso puedo afirmarlo de ellas con certeza e independientemente del hecho de que su posición misma sea legítima o $\mathrm{no}^{55}$.

En Introducción a la filosofía, la comprensión de certeza entonces todavía se verifica por el hecho de que "cuanto mayor sea el número de casos en que esa ley se confirma, tanto mayor es la certeza con que se la establece como un hecho universal" ${ }^{\prime 6}$, es decir, por un criterio cuantitativo, ya que la comprensión de la certeza se mantiene a un

\footnotetext{
${ }^{50}$ Ibíd., 16 [681, Nota 23].

${ }^{51}$ Ibíd., 78 [749].

${ }^{52}$ Ibíd., 95 [768].

${ }^{53}$ Ibíd., 95 [768].

${ }^{54}$ Ibíd., 163 [838ss.]

${ }^{55}$ Ibíd., 166 [843].

${ }^{56}$ Ibíd., 204 [882].
} 
nivel empírico medible, sin ser remontada a la experiencia originaria de ser como en Acto y potencia.

\section{La certeza mayor en ¿Qué es filosofía?}

La obra ¿Qué es filosofía? Un diálogo entre Edmund Husserly Tomás de Aquino, da cuenta de un desplazamiento de comprensión de la certeza absoluta del campo de la filosofía hacia la certeza mayor de la fe. Sin embargo, en términos de Tomás:

...el método que procede a excluir la fe es enteramente comprensible, si por fe se entiende un sentimiento o, en general, algo "irracional" [...]. Pues cosa de la ratio es la filosofía [...] en el amplio sentido de razón que comprende a la natural y a la sobrenatural...57

[Es decir] un camino para alcanzar verdades que de otro modo nos estarían vedadas $y$, en segundo lugar, el camino más seguro hacia la verdad, puesto que no hay certeza mayor que la de la fe. Aún más: no hay para los hombres in statu viae ningún conocimiento de certeza comparable a la propia de la fe, aunque esta sea una certeza no intelectual. De este modo, la fe gana un doble significado para la filosofía. ${ }^{58}$

En otras palabras, "una dependencia material de la fe "39 y "también una dependencia formal de la fe $e^{60}$; pero "la específica certeza de la fe es un regalo de la gracia" ${ }^{61}$.

Si bien Tomás advierte a Husserl aquella verdad, que surge connaturalmente desde Acto y potencia, ella es desconocida por la filosofía moderna, que "pretende bastarse a sí misma con la razón natural". Pero:

Nosotros tenemos desde el principio la certeza absoluta que se necesita para erigir un edificio sólido; ustedes tienen que buscar primero un punto de partida semejante: siendo así se comprende perfectamente que la crítica del conocimiento debería llegar a ser, en la filosofía moderna, la disciplina fundamental y que a ella se orientaran los principales esfuerzos de los grandes filósofos. Esto mismo le ha sucedido a usted. Partiendo de problemas particulares se vio obligado a retroceder paso a paso y a esforzarse en asegurar un método absolutamente fiable [...]. Con todo, no pudo usted descansar aquí. ${ }^{62}$

La certeza de ser emerge entonces en ¿Qué es filosofía? desde los pasos del método husserliano, descrito por Tomás, que le llevan a afirmar al respecto su "teoría del conocimiento":

\footnotetext{
${ }^{57}$ Ídem, Was ist Philosophie? 98 [¿Qué es filosofía?18].

${ }^{58}$ Ibíd., 98 [18].

${ }^{59}$ Ibíd., 98 [18ss.].

${ }^{60}$ Ibíd., 98 [19].

${ }^{61}$ Ibíd., 99 [20].

${ }^{62}$ Ibíd., 100 [21].
} 
En la apacible certeza de que a nuestra disposición hay una serie de medios cognoscitivos legítimos, me fue lícito hacer uso de todos ellos sin vacilar, para enriquecerme con el tesoro de conocimientos filosóficos más grande posible. Para mí se trataba del qué, no del cómo. ${ }^{63}$

Esta distinción tomasiana conlleva otra, pues "de la distinta determinación del objetivo y la distinta concepción de los fundamentos de la certeza tenía que derivarse una distinta orientación de la filosofía en su conjunto" ${ }^{\text {"4 }}$.

\section{La certeza de "lo experimentado interiormente" en La estructura de la persona humana}

En La estructura de la persona humana, síntesis de la docencia de Stein durante 1931 y 1932, centrada en la visión de la estructura de la persona humana armónica con proyección antropológico-pedagógica concreta, la autora presta atención a la "certeza empírica”. Esto significa:

...en el caso de otras funciones corporales, diversas experiencias y observaciones permiten establecer con certeza empírica la dependencia de lo corporal respecto de lo anímico. Y si muecas y gestos poseen un valor simbólico y constituyen "un lenguaje del alma", rico y muy desarrollado, que nos permite leer en ella, siempre hay un mecanismo corporal. ${ }^{65}$

Tal certeza empírica, ligada a la estructura corporal de la persona humana, atendida también en Acto y potencia, se plasma de modo consecuente a nivel espiritual eucarístico, como una certeza de fe. Stein constata:

Para quien viva así, la fe en la eucaristía ya no será asentimiento a algo ajeno y exterior movido por una autoridad externa, sino la certidumbre de lo experimentado interiormente, de lo que se ha convertido en parte inseparable del propio ser. ${ }^{66}$

Esta certeza "de lo experimentado interiormente" abre, en definitiva, la certeza hacia su fundamento trascendente.

Para sintetizar, cabe apreciar accesos a la certeza de ser, en continuidad discontinua con el de Acto y potencia, que la plasman en cuanto comprendida de modo incipiente, pero no distinta de la que Stein explica en Acto y potencia. Solo que las obras Introducción a la filosofía, ¿Qué es filosofía? y La estructura de la persona humana

\footnotetext{
${ }^{63}$ Ibíd., 101 [22].

${ }^{64}$ Ibíd., 103 [25].

${ }^{65}$ Ídem, Der Aufbau der menschlichen Person, 105 [La estructura de la persona humana, 127].

${ }^{66}$ Ibíd., 166 [201].
} 
señalan aspectos metódicos importantes, similares a lo señalado por Wittgenstein a nivel lógico práctico, con atención a la duda en cuanto "alabanza" de Berger, de todos modos incompletos en comparación con la de la certeza simple de ser en Acto y potencia, pero que abren caminos hacia el fundamento de la certeza en cuanto simple hecho de ser, no del todo perfilado.

\section{El fundamento de la certeza simple de ser y su búsqueda en Sobre el problema de la empatía, Causalidad psíquica y Castillo interior}

El fundamento de la certeza simple de ser, radicalmente cuestionado hoy ${ }^{67}$, que Stein logra dilucidar en Acto y potencia en cuanto punto de arranque de todo método científico, cuenta con significativas alusiones steineanas desde la tesis doctoral Sobre el problema de la empatía -aunque tenuemente invocado-, hacia un mayor relieve explicitado en Causalidad psíquica, para completarse en Castillo interior.

\section{Lo indubitable y la certeza simple de ser en Sobre el problema de la empatía}

Cuando Stein se refiere a la certeza en Sobre el problema de la empatía, la interrelaciona con "lo indubitable" del conocimiento del fenómeno:

...en lo que debe estar últimamente anclado todo conocimiento y certezaGewissheit [...]. Aprehender el fenómeno en su esencia pura, desligado de todas las contingencias del aparecer, es por tanto la primera tarea que en esta, como en otras áreas, ha de solventarse. ${ }^{68}$

Previo a la certeza lógica de las obras analizadas-Introducción a la filosofía, ¿Qué es filosofía? y La estructura de la persona humana- la autora sitúa entonces la certeza en el contexto del ser y su índole "indubitable" en cuanto realidad.

\footnotetext{
${ }^{67}$ Según lo que Habermas constata respecto a Derrida, nunca ha existido tal libro escrito de puño y letra de Dios, sino solo rastros de él y aun estos borrosos. Esta conciencia marca la autocomprensión de la Modernidad, al menos desde el siglo XIX: "No es solo que hayamos perdido la certeza teológica de ver cómo toda página se encuaderna de por sí en el texto único de la verdad [...], 'libre de raison' como se llamaba antaño al diario en que se consignaban para memoria las cuentas, las relaciones y la experiencia, recopilación genealógica, libro de la razón esta vez, manuscrito infinito leído por un Dios que de forma más o menos diferida nos hubiera prestado su pluma. Esta certeza perdida, esta ausencia de la escritura divina, es decir, esta ausencia ante todo del Dios judío, que en ocasiones escribía él mismo, no define solamente y vagamente algo así como la 'Modernidad'. En cuanto ausencia del signo divino y obsesión por el signo divino, determina toda la estética y la crítica modernas" (Habermas, El discurso filosófico de la Modernidad, 182).

${ }^{68}$ Stein, Zum Problem der Einfüblung, 34 [Sobre el problema de la empatía, 37].
} 
Pese a que se trata aquí de la certeza -Gewissheit- a nivel cognoscitivo, ella involucra el "estar cierto" de un "conocer la persona" a través de "la empatía". Es la comprensión empatizante del otro, el individuo espiritual ajeno, la que permite tener "la posibilidad de traerme a dato su comportamiento en ciertas circunstancias, comportamiento que no está atestiguado. Este actuar está reclamado por la estructura de su persona que tengo la certeza de conocer"69.

Desde el ser -sin abandonarlo- Stein transita a la comprensión de la certeza dentro del marco de la intersubjetividad, el ser de frente al yo, el otro, la persona -tránsito evidente en Acto y potencia y sobre todo en Ser finito y ser eterno-, pero cuyo fundamento queda esbozado en Sobre el problema de la empatía y permanece vigente, aunque radicalizado, a lo largo de toda la obra steineana hasta Ciencia de la cruz.

Resulta decisiva la necesidad de discernir la experiencia en el terreno de lo religioso, cuya respuesta definitiva la autora deja abierta, cuando pregunta: “¿Mas no está también dada ya con las imágenes ilusorias de tal experiencia la posibilidad esencial de experiencias auténticas en este terreno?” Y contesta: “En cualquier caso, el estudio de la conciencia religiosa me parece el medio más adecuado para la respuesta a nuestra cuestión, como por otro lado es su respuesta del más alto interés para el terreno religioso". Pero concluye: "Mientras tanto, cedo a investigaciones ulteriores la respuesta de la pregunta planteada y que conformo aquí con un non liquet"70. Tal constatación clave para la certeza simple de ser, se concreta luego en "otra certeza" en Causalidad psíquica.

\section{La experiencia de la "otra certeza" en Causalidad psíquica}

Stein explica la posibilidad de la existencia de un fundamento último de la empatía mediante un análisis del concepto de lo psíquico a la luz de la "filosofía como ciencia exacta", con facetas propias de la causalidad y su legalidad psíquica. Esto permite reconocer el género "sentimiento vital", que abarca todos los sentimientos vitales posibles, el género "tensión del acto de vivenciar", "al que pertenecen todos los grados de tensión", de tal modo que "debe reconocérselos con certeza totalmente indubitable y sin confundirlos unos con otros"71 en el campo de la actividad del yo ${ }^{72}$.

Según Stein, tal actividad, interrelacionada con la motivación en cuanto explicación de la causalidad psíquica en el ámbito de la toma de conocimiento, posibilita

\footnotetext{
${ }^{69}$ Ibíd., 130 [130].

${ }^{70}$ Ibíd., 136 [135].

${ }^{71}$ Ídem, Psychische Kausalität, 33 [Causalidad psíquica, 249].

${ }^{72}$ Ibíd., 33 [249].
} 
la experiencia religiosa como un "volverse hacia el objeto, del que ya se me concedió cierto conocimiento, y el progresar hacia ulteriores daciones. Las tomas de posición son algo de lo que se me hace 'partícipe' [...]. 'Toman posesión de mí’”73.

Sin embargo: "Por otro lado yo no puedo anhelar para mí una fe religiosa, puedo esforzarme por ella con todas mis energías y puede ser que esa fe no se me conceda" 74 . Sin embargo,

...existe una posibilidad que no se da en las simples tomas de conocimiento: puedo "tomar posición" en un sentido nuevo, ante las tomas de posición; puedo acogerlas, situarme en su terreno, profesar mi creencia en ellas o comportarme con rechazo hacia ellas. Las acepto, es decir, me entrego a ellas, cuando surgen en mí, y lo hago gozosamente, sin resistirme. Las rechazo, esto no significa: las elimino. Eso no se halla en mi poder. ${ }^{75}$

No cabe duda de que Stein se refiere a la posibilidad de una experiencia radical de fe religiosa en cuanto fundamento imborrable de la certeza de ser; pero resulta importante que se trata no de un mero conocimiento, sino de una experiencia interrelacionada con los motivos del sujeto. De ahí que la autora explica que, para la "cancelación" de una creencia, se necesitan nuevos motivos, que quitan su vigor a los motivos de la creencia original y de los cuales la creencia vuelva a emerger "por sí misma"76. Esto lo explicita en un ejemplo concreto:

Consideramos el caso de un ateo convencido que, en una vivencia religiosa, siente íntimamente la existencia de Dios. No es capaz de sustraerse a la fe, pero no se sitúa en el terreno de la misma. No deja que esa fe llegue a ser eficaz en él; permanece inmutable en su "concepción científica del mundo y de la vida”, una concepción que caería por tierra si él aceptara abiertamente la fe. ${ }^{77}$

Se aprecia la complejidad de la experiencia psíquica, que origina la certeza simple de ser en cuanto no solo involucra el sentir -señalado en Acto y potencia- sino también el "querer" del sujeto.

Una mayor complejidad de la experiencia del fundamento último de la certeza simple de ser todavía emerge del primer indicio de la conversión de Stein a la fe católica, en cuanto "otra certeza". La autora describe así

...un estado de reposo en Dios, de completa relajación de toda actividad espiritual, en el que no se hace ninguna clase de planes, no se adoptan re-

\footnotetext{
${ }^{73}$ Ibíd., 43 [261].

${ }^{74}$ Ibíd., 43 [261].

${ }^{75}$ Ibíd., 43 [261].

${ }^{76}$ Ibíd., 43 [261].

${ }^{77}$ Ibíd., 43 [261].
} 
soluciones, y menos aún se actúa, sino que todo lo futuro se deposita en manos de la voluntad divina, "se abandona" por completo "al destino". Este estado se me concede, por ejemplo, cuando una vivencia que sobrepasaba mis energías ha consumido por completo mi energía vital espiritual y me ha arrebatado toda "actividad" en cuanto "descanso en Dios" [...].

[Tal "descanso"] es algo completamente nuevo y singularísimo. Aquel silencio propio de muertos. En lugar de él aparece ahora el sentimiento de hallarse acogido, de estar liberado de toda preocupación y responsabilidad y obligación de actuar y cuando yo me entrego a este sentimiento, comienza a llenarme poco a poco nueva vida y vuelve a impulsarme -sin tensión alguna de la voluntad- a nueva actividad y una energía que no son mías, y que actúan en mí sin imponer exigencia a las mías. El único presupuesto para semejante renacimiento espiritual parece ser cierta capacidad receptiva, como la que se fundamenta en la estructura de la persona que se ha sustraído a la acción del mecanismo psíquico. ${ }^{78}$

La "otra certeza" va ligada entonces a un cese de actividades psíquicas y un renacer nuevo; es decir, está en juego la vida en su estrato más vital, que todavía permite aumento de certeza en cuanto "grandísima".

\section{La certeza grandísima en el Castillo interior}

La experiencia del fundamento de la "otra certeza" llega a su consumación en Castillo interior -texto anexo al Ser finito y ser eterno-, y destaca su índole mística, es decir, secreta: "El alma jamás ve este secreto misterio, mientras se realiza en ella, pero 'lo ve después claro'; y no porque es visión, sino una certidumbre que queda en el alma, que solo Dios puede poner" $(5 \mathrm{M} \mathrm{1,10})^{79}$. "De ahí que si esas hablas se refieren a cosas futuras, deriva de ellas una 'certidumbre grandísima' de que se cumplirán aun cuando su cumplimiento tarde años o llegue a parecer imposible" ${ }^{80}$.

Llama la atención que aquí el término certidumbre, de menor precisión conceptual, aunque no menos "cierta", reemplaza a la "certeza" más delimitable, tanto en Acto y potencia como en la obras steineanas analizadas al respecto.

Pese a tal certeza regalada de parte de Dios al alma humana, "ella misma no se tiene por segura, sino que anda 'con mucho más temor que antes' y se guarda 'de cualquier pequeña ofensa de Dios"” $(7 \mathrm{M} 2,9)^{81}$. Tal inseguridad en la seguridad es ciertamente signo de que la certeza de ser simple sigue inserta en la temporalidad

\footnotetext{
${ }^{78}$ Ibíd., 73 [298].

${ }^{79}$ Ídem, Die Seelenburg, 509 [Castillo interior, 87].

${ }^{80}$ Ibíd., 513 [92].

${ }^{81}$ Ibíd., 519 [98].
} 
que la autora describe magistralmente en Acto y potencia, aun en el estado místico, pues "cuanto más hondamente el alma se sumerge en el espíritu y más firmemente se instala en su centro, tanto más libremente puede elevarse sobre sí misma y liberarse de las ataduras materiales" ${ }^{\prime 2}$.

En sintesis, es válido que la argumentación en las obras Sobre el problema de la empatía, Causalidad psíquica y Castillo interior confirma lo destacado en Acto y potencia respecto del fundamento último de la intersubjetividad y la tan distinta causalidad psíquica abierta a la experiencia de Dios, explicitando facetas de la experiencia de "otra certeza" "grandiosa" en su índole positiva, pero sí parecidas ya a las "certezas negativas", desarrolladas por Marion, que pueden ser consideradas un transfondo iluminador para comprender a continuación la índole kenótica en Naturaleza, libertad y gracia y Ciencia de la cruz.

\section{La concreción de la certeza simple de ser y su vertiente kenótica en Naturaleza, libertad y gracia y Ciencia de la cruz}

La certeza simple de ser, en Acto y potencia y Ser finito y ser eterno, recibe una significativa concreción en Naturaleza, libertad y gracia (escrita probablemente entre 1916-1918 o en 1921, y considerada, pese a su brevedad, uno de los escritos steineanos más importantes), y sobre todo en Ciencia de la cruz, obra cumbre, a partir de la interrelación de dicha certeza con la fe y un nuevo concepto de "espíritu".

\section{La fe y la certeza simple en Naturaleza, libertad y gracia}

En Naturaleza, libertad y gracia, la certeza, articulada a partir del "sentir" en Acto y potencia, se interrelaciona con el sentimiento, pero más que con el vocablo sentir con el de "notar" (spüren). Cuando Stein se refiere a "la organización psicofísica como punto de incidencia de los efectos salvíficos" ${ }^{3}$, designa la fe "certidumbre que inhiere en la captación de un ser existente realiter o idealiter también en el correspondiente conocimiento" ${ }^{84}$, que "en ciertos actos como un momento que los constituye" y "denominamos certidumbre o bien con el término técnico introducido belief" ${ }^{55}$. Pese a que "la fe en Dios sí tiene este carácter de absoluta", "podemos perderla, pero ella no

\footnotetext{
${ }^{82}$ Ibíd., 525 [106].

${ }^{83}$ Ídem, "Freiheit und Gnade" 60-72 [Naturaleza, libertad y gracia, 117-128].

${ }^{84}$ Ibíd., 60 [117].

${ }^{85}$ Ibíd., 60-61 [117-118].
} 
puede modificarse". "Pero esos no son grados de certidumbre de la fe, sino un más o menos del sostenerse firmemente y en correspondencia con ello del sentirse sostenido" ${ }^{\text {"6 }}$.

Tal "sentirse sostenido", regalado por Dios -distinto que a nivel humanosignifica que estamos "ante la certidumbre absoluta y caracterizada en sí misma como absoluta". Si bien "las esperanzas motivadas por la fe en él pueden decepcionar siempre, y eso contiene a ese hombre mismo en un momento de incertidumbre que está excluido de la fides" ${ }^{87}$,

.... la belief le corresponde en el acto religioso fundamental lo que denominábamos certidumbre de la fe. Pero este momento se distingue de la belief por su carácter de absoluto y porque resulta imposible por principio pasar de él a otros caracteres, como la duda u otros semejantes. ${ }^{88}$

Stein se detiene en la "captación" de tal certidumbre como en un "ser tocado por la mano de Dios en virtud del cual lo que nos toca está presente frente a nosotros"...

Frente a esa primera captación hay un comportamiento libre. Si cojo la mano que me toca encuentro el sostén absoluto y el amparo absoluto. El Dios todopoderoso está ahora ante nosotros como un Dios que es todo bondad, como "nuestro refugio y fortaleza". El amor a él nos inunda y nos sentimos llevados por su amor. Coger la mano de Dios y sostenerla es la obra que co-constituye el acto de fe. ${ }^{89}$

El fundamento de su certidumbre es la fe en la veracidad de quien hace la comunicación $[\ldots]$ evidente. ${ }^{90}$

En esta "certidumbre de la fe", que "se distingue tanto como la certidumbre absoluta de la fides se distingue de la belief ${ }^{91}$, hay que afianzarse y avanzar por el camino del "sostenerse en Cristo", que "no se puede hacer sino seguirle"

\section{La certeza simple de ser y su dimensión trinitaria en Ciencia de la cruz}

En Ciencia de la cruz, la última obra, de compleja gestación literaria y finalizada antes de la muerte de Edith Stein, la comprensión de la certeza simple del ser confluye con

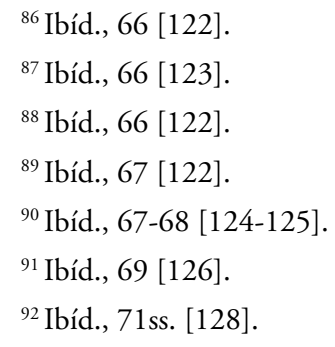


el sentimiento en Juan de la Cruz a partir de la "ciencia de la cruz" ${ }^{93}$, propia de la Sagrada Escritura, en su dimensión trinitaria y concreción cristológica, basada en una nueva visión del espíritu, la "ontología del espíritu”"

Dicha ontología "lleva luz al alma: un saber de completa seguridad -Gewissheit- que supera cualquier otra ciencia y conocimiento, de tal modo que solo en la contemplación perfecta podemos alcanzar una correcta idea de la fe... (Is 7,9)"95. Lo que entra por los sentidos, es comprendido por el corazón (1Co 2,9) "que aquí significa el alma"96, "se imprimen profundamente en el alma y despiertan un convencimiento inquebrantable de su verdad"

Tal "comprender con el corazón" es la forma de amor, que siente no sintiendo y "así queda el alma amando a lo cierto" "98 "segura de los más astutos planes y acechanzas del demonio" 99 , ya que "así es mucho lo que importa para la seguridad del alma que el trato interior con Dios se dé de manera que sus mismos sentidos de la parte interior queden a oscuras" [...] "y más segura paz"100, "sintiéndolo ella claramente y holgándose de verse tan a lo seguro gozar de aquella quieta paz"101 "su seguro lugar de descanso". "Quien vive con la certeza de esta creencia -Glaubensgewissheit- no puede ya, en su conciencia, quedar tranquilo en el propio "mejor saber" -besten Wissen-102, "sino dejarse guiar y llevar por el espíritu de Dios -Geist Gottes- que perceptiblemente le está empujando, y tiene en todo lugar y momento, la seguridad -Gewissheit- de hacer lo que debe" ${ }^{103}$.

"Mientras duraba el misterioso fenómeno, ella no lo ha notado. Pero después bien ha reconocido con seguridad su realidad" [...] "una certidumbre que queda en el alma que sólo Dios la puede poner". "Pues ¿cómo lo que no vimos se nos queda con esa certidumbre?" ${ }^{104}$. "Sin ella proponérselo la santa madre ha hecho algunos intentos de explicación" de "la inhabitación divina, que ella sentía con una certidumbre tan

${ }_{93}^{9}$ Ídem, Kreuzeswissenschaft, 28-31; 205 [Ciencia de la cruz, 230-233].

${ }^{94}$ Ibíd., 46 [249].

${ }^{95}$ Ibíd., 48 [250].

${ }^{96}$ Ibíd., 49 [251].

${ }^{97}$ Ibíd., 61 [264].

${ }^{98}$ Ibíd., 75 [27].

${ }^{99}$ Ibíd., 122 [329].

${ }^{100}$ Ibíd., 127 [329].

${ }^{101}$ Ibíd., 127 [329].

${ }^{102}$ Ibíd., 137 [329].

${ }^{103}$ Ibíd., 138 [329].

${ }^{104}$ Ibíd., 142 [351]. 
irrefragable como la inhabitación común a todos los seres creados". "Quien no quedare con esta certidumbre, no diría yo que es unión de toda el alma con Dios". "El alma tiene la certidumbre de que ella estuvo en Dios y Dios en ella" 105 .

Pero esto no es todo. Stein, al citar a Teresa, insiste: “ $¡ O$ Oh almas que os queréis andar seguras -Sicherheit- y consoladas en las cosas del espíritu! Si supiéses cuánto os conviene padecer sufriendo para venir a esa seguridad -Sicherheit- y consuelo..." ${ }^{106}$. Sin embargo, "el alma espera esta beata plenitud con la profunda paz de la certeza -im tiefen Frieden der Gewissheit- de estar completamente preparada y de no tener nada que temer por ninguna parte"107. De ahí que "el camino más oscuro es el más seguro"

La certeza simple de ser, punto de partida de toda "ciencia estricta", según Acto y potencia, también es entonces punto de llegada de "la ciencia de la cruz" en cuanto culmen de la comprensión steineana de dicha certeza anterior y posterior a Acto y potencia. Como tal emerge de la interioridad de la visión del "espíritu nuevo" como una certeza "negativa", en términos de Marion, con el rostro de profundidad indubitable del Resucitado.

\section{A modo de conclusión}

Puede constatarse que la dilucidación de certeza/certidumbre -Gewissheit- y seguridad -Sicherheit- logra armonizar, metódicamente, ambos conceptos:

1. La certeza de ser trasciende la razón humana en su indole clara y distinta, no se restringe al ámbito propio de la razón y, sin embargo, se gesta a partir de una racionalidad criticada desde su índole simple de ser. Tal índole óntica se distingue de la comprensión de la certeza en Wittgenstein, quien la articula a través de la acción. De tal modo, es preciso reconocer que dicha certeza se gesta al interior de la razón a partir del "hecho de ser", Seinstatsache.

2. Si bien la certeza arraiga en el sentir más allá del cual no puede retrocederse, el sentimiento no es la última explicación de la certeza, ligada al afecto por las instituciones, que a Berger le lleva a incluir la duda en la certeza, a modo hímnico. Entonces la certeza supera al sentimiento, sin tener su anclaje definitivo en él.

3. La certeza simple de ser representa una novedad que emerge entre ambos, razón y sentimiento. Esto queda avalado gracias a un análisis de la existencia finita del ser humano, que interrelaciona la finitud con la temporalidad y su dinámica dual de

\footnotetext{
${ }^{105}$ Ibíd., 143 [351].

${ }^{106}$ Ibíd., 169 [370].

${ }^{107}$ Ibíd., 225 [438].

${ }^{108}$ Ibíd., 231 [445].
} 
acto y potencia, al trasluz de la eternidad, en contraposición a Derrida, analizado por Habermas.

4. La novedad de la comprensión steineana emerge, en definitiva, del espíritu finito en cuanto anticipado por su fundamento absoluto, el Espiritu infinito, que revierte la negatividad de la certeza en la certidumbre facial de Marion, sobre todo a partir de los rasgos inaferrables del "rostro" infinito, que se desvela en la intimidad más profunda de la peculiaridad del ser individual como fundante en cuanto sostén insoslayable de su peculiaridad, transparente a la universalidad del ser, que el ser singular concreto tiene en común con todos los seres.

5. Si bien la certeza simple de ser se plasma a partir del "núcleo de la persona” en cuanto anticipado por su fundamento último, el Espiritu infinito, recién a partir de la entrega del espíritu finito al Espiritu infinito, al modo del Espiritu Santo, garante último de la certeza simple de ser, se realiza aquella plenitud de la certeza de la resurrección, que el papa Francisco recientemente evocó.

\section{Bibliografía}

Abbagnano, Nicola. "Certidumbre o certeza". En Diccionario de filosofia (2a. ed.), dirigido por N. Abbagnano, 159-161. Mexico-Buenos Aires: Fondo de Cultura Ecónomica, 1966.

Berger, Peter y Anton Zijderveld. In Praise of Doubt. How to Have Convictions Without Becaming a Fanatic. New York: Harper Collins Publishers, 2009.

Fermandois, Eduardo. "Ni fundacionismo ni coherentismo. Una lectura antropológica de Sobre la certeza". Revista de Filosofía 69 (2013): 99-117.

Francisco. "La certeza de la resurrección". Humanitas 20 (2015): 625-626.

Habermas, Jürgen. El discurso filosófico de la Modernidad. Buenos Aires-Madrid: Katz, 2008.

Halbfass, Wilhem. Historisches Wörterbuch der Philosophie. Vol. 3. Basel-Stuttgart: Schwabe, 1971.

Marion, Jean-Luc. Certitudes Négatives. Paris: Grasset, 2010.

Meis, Anneliese. "El espíritu finito, anticipado por el Espíritu infinito en la obra Potenz und Akt de Edith Stein". Scripta Theologica 47 (2015): 9-40.

Naaykens, Bernard. “El fundamento de nuestra certeza”. Scripta Theologica 12 (1980): 171-194.

Stein, Edith. “Acto y potencia”. En Obras completas, por E. Stein, Vol. III, 225-536. Burgos: Monte Carmelo 2005. 
. Anhang: Martin Heideggers Existenzphilosophie. Die Seelenburg. Introducido y editado por Andreas Uwe Müller. Freiburg- Basel-Wien: Herder, 2006.

. "Castillo interior". Anexo de Ser infinito, ser eterno. En Obras completas, por E. Stein, Vol. III, 1113-1136. Burgos: Monte Carmelo 2005.

. Ciencia de la cruz. Estudio sobre San Juan de la Cruz. Burgos: Monte Carmelo, 1989.

. "Causalidad psíquica”. En Obras completas, por E. Stein, Vol. II, 217-329. Burgos: Monte Carmelo 2005.

. "Die Seelenburg”. En Anhang: Endliches und ewiges Sein. Versuch eines Aufstiegs zum Sinn des Seins, 501-525. Freiburg: Herder, 2006.

. Der Aufbau der menschlichen Person. Vorlesung zur philosophischen Anthropologie. Freiburg-Basel-Wien: Herder, 2004.

. Einführung in die Philosophie. Freiburg-Basel-Wien: Herder, 2004.

. Endliches und ewiges Sein. Versuch eines Aufstiegs zum Sinn des Seins. FreiburgBasel-Wien: Herder, 2006.

. Freiheit und Gnade und weitere Texte zu Phänomenologie und Ontologie (1917 bis 1937). Freiburg- Basel-Wien: Herder, 2014.

. Gesamtausgabe, hrsg Internationales Edith Stein. 26 vols. Freiburg-BaselWien: Herder, 2004-2008.

. "Introducción a la filosofía". En Obras completas II. Escritos filosóficos. Etapa fenomenológica, por E. Stein, 657-913. Burgos: Monte Carmelo, 2005.

. Kreuzeswissenschaft. Sudie über Johannes vom Kreuz. Freiburg-Basel-Wien: Herder, 2003.

. La estructura de la persona humana. Madrid: Biblioteca de Autores Cristianos, 2002.

. "Naturaleza, libertad y gracia". En Obras completas, por E. Stein, Vol. III, 55128. Burgos: Monte Carmelo 2005.

. Potenz und Akt. Studien zu einer Philosophie des Seins. Freiburg-Basel-Wien: Herder, 1998.

. "Psychische Kausalität". En Beiträge zur philosophischen Begründung der Psychologie und der Geisteswissenschaften, por E. Stein, 1-109. Freiburg: Herder, 2010. 
- ¿Qué es filosofía? Un diálogo entre Edmund Husserl y Tomás de Aquino. Madrid: Encuentro, 2001.

- "Ser finito y ser eterno. Ensayo de una ascensión al sentido del ser". En Obras completas, por E. Stein, Vol. III, 587-1112. Burgos: Monte Carmelo 2005. . Sobre el problema de la empatía. Madrid: Trotta, 2004.

. "Was ist Philosophie? Ein Gespräch zwischen Edmund Husserl und Thomas von Aquino (1928)". En Freiheit und Gnade und weitere Beiträge zu Phänomenlogie und Ontologie (1917-1937), por E. Stein, 91-142. FreiburgBasel-Wien: Herder, 2014.

. Zum Problem der Einfühlung. Freiburg-Basel-Wien: Herder, 2008.

Wittgenstein, Ludwig. Sobre la certeza. Barcelona: Gedisa, 1988. 
